\title{
BatMon II: Children's category norms for 33 categories
}

\author{
HEATHER L. PRICE and DEBORAH A. CONNOLLY \\ Simon Fraser University, Burnaby, British Columbia, Canada
}

\begin{abstract}
Four hundred forty-eight children 3-12 years of age generated category exemplars for 33 distinct categories. The percentage of the participants reporting each exemplar, the percentage of the participants reporting each exemplar first, the percentage of the participants reporting each exemplar across age groups (3-5 years, 6-8 years, and 9-12 years), and the mean rank of each exemplar are presented. A full version of the 29 category norms may be downloaded from www.psychonomic.org/archive.
\end{abstract}

Children's ability to recognize similarities across objects and to classify objects into distinct categories is fundamental to cognitive development (see, e.g., Rakison \& Oakes, 2003). Many studies rely on prior research on knowledge of the contents of common categories for the development of research materials (e.g., Connolly \& Price, 2006). For instance, to manipulate the level of prototypicality of an item as an exemplar of a category, it is important to understand what items children generally believe belong in a category. In 1969, Battig and Montague conducted a seminal study on category norms in adults. These data have been used extensively in subsequent research. The Battig and Montague methodology has been replicated (with some variations) in varying populations, including American college students (Shapiro \& Palermo, 1970), Flemish and Dutch university students (Storms, 2001), New Zealand university students (Marshall \& Parr, 1996), and Australian university and community samples (Casey \& Heath, 1988). All of these studies tested an adult sample. Because knowledge of categories develops throughout the childhood years, it is reasonable to expect that children's and adults' knowledge of category exemplars may differ. Although the Battig and Montague methodology has been used with children (Posnansky, 1978), the only study we were able to locate is now somewhat outdated and employed a methodology that may have influenced children's responses (i.e., because children as young as 7 years old recorded their own responses, they may have selected exemplars that were easier to write, rather than the first ones that came to mind). The present study

This research was supported by a Natural Sciences and Engineering Research Council of Canada PGS-A grant to the first author and by a Social Sciences and Humanities Research Council of Canada Research grant to the second author. The authors thank all the research assistants who helped with this project, especially Andreea Arsenie, Pam Johnson, Melissa Northcott, and Scott Currie. We also thank the parents, teachers, and children who enthusiastically participated in this research. Correspondence concerning this article should be addressed to H. L. Price, Department of Psychology, Simon Fraser University, 8888 University Dr., Burnaby, BC, V5A 1S6 Canada (e-mail: hlprice@sfu.ca). replicated Battig and Montague's methodology, with only minor changes because the participants were children.

\section{METHOD}

\section{Participants}

To approximate the size of the Battig and Montague (1969) data, the sample included 448 children 3-12 years of age from elementary schools, preschools, daycares, and summer camps in the Greater Vancouver area. We tested children throughout the preschool and elementary school years in order to gather as broad a sample as possible. The children were divided into three age groups for comparison of category norms: preschoolers ( $3-5$ years of age; $n=119 ; M$ age $=4.43$ years, $S D=0.65$; females, $n=57$; males, $n=62$ ), early primary school children (6-8 years of age; $n=191 ; M$ age $=7.04$ years, $S D=0.84$; females, $n=87$; males, $n=104$ ), and late primary school children (9-12 years of age; $n=138, M$ age $=9.59, S D=0.71$; females, $n=$ 66; males, $n=72$ ). Due to the greater interest in participation shown by Grade 1 and Grade 2 teachers, there was an overrepresentation of children in the 6-8 years age group. Most of the children were born in Canada (85.7\%) and $4.9 \%$ were born in Asia, with the remaining $8.1 \%$ being born in a broad collection of other countries. The first 43 children were asked to provide responses to 11 of the total 33 categories: The distribution of ages across the age groups was approximately even, and approximately the same number of children responded to each category. However, once it had been determined that the children could sustain attention for all 33 categories, the remaining children were asked to respond to all 33 categories.

\section{Procedure}

The children were tested individually in sessions that lasted approximately 20-30 $\mathrm{min}$ (for the children who generated exemplars for all 33 categories). At the beginning of the session, the children were told that they would play a word game in which the researcher would provide them with a word(s) and they were to respond by listing all the words they could think of that went with the provided word. Each child was then given an example: "If I said to you, tell me all the different movies you can think of, what would you say?" The children practiced examples (none of the practice categories were those for which the children subsequently generated exemplars) until they had demonstrated that they understood the game. Fewer than 10 children required more than one practice example. Next, the children were asked to generate exemplars by saying the items for each of 33 categories (listed in Table 1). If the category name was sophisticated, the children were provided with a brief description of the category (e.g., the beverages category was described as "things you can drink"). For 
Table 1

Number of Distinct Exemplars Generated per Category and Number of Children Responding

\begin{tabular}{|c|c|c|c|c|c|c|}
\hline \multirow{2}{*}{$\begin{array}{l}\text { Table Number } \\
\text { and Category }\end{array}$} & \multicolumn{3}{|c|}{ No. of Children Responding } & \multicolumn{3}{|c|}{ No. of Distinct Exemplars } \\
\hline & $3-5$ Years & $6-8$ Years & $9-12$ Years & $3-5$ Years & $6-8$ Years & 9-12 Years \\
\hline 2. Animals & 111 & 169 & 130 & 140 & 154 & 177 \\
\hline 3. Beverages & 113 & 173 & 127 & 100 & 103 & 114 \\
\hline 4. Boys' names & 100 & 164 & 128 & 250 & 270 & 288 \\
\hline 5. Candy & 109 & 168 & 126 & 184 & 167 & 180 \\
\hline 6. Cartoon characters & 101 & 158 & 119 & 230 & 229 & 244 \\
\hline 7. Colors & 110 & 171 & 127 & 55 & 66 & 61 \\
\hline 8. Exercises & 95 & 158 & 123 & 98 & 115 & 117 \\
\hline 9. Family members & 107 & 171 & 127 & 81 & 104 & 98 \\
\hline 10. Fruits & 106 & 169 & 128 & 53 & 67 & 65 \\
\hline 11. Furniture & 100 & 160 & 125 & 109 & 134 & 140 \\
\hline 12. Girls' names & 99 & 163 & 126 & 292 & 301 & 328 \\
\hline 13. Grocery store items & 105 & 168 & 127 & 225 & 242 & 223 \\
\hline 14. Ice cream flavors & 111 & 169 & 128 & 101 & 113 & 113 \\
\hline 15. Insects & 106 & 165 & 126 & 74 & 72 & 79 \\
\hline 16. Jobs & 119 & 176 & 131 & 239 & 282 & 320 \\
\hline 17. Musical instruments & 109 & 164 & 124 & 69 & 81 & 82 \\
\hline 18. Outside games & 110 & 169 & 128 & 145 & 163 & 158 \\
\hline 19. Parts of the body & 100 & 168 & 124 & 103 & 103 & 134 \\
\hline 20. Pets & 91 & 157 & 124 & 78 & 86 & 95 \\
\hline 21. Pieces of clothing & 106 & 157 & 121 & 148 & 97 & 122 \\
\hline 22. Places to play & 112 & 172 & 127 & 161 & 233 & 160 \\
\hline 23. Presents & 109 & 142 & 114 & 251 & 199 & 284 \\
\hline 24. Shapes & 102 & 166 & 127 & 63 & 61 & 71 \\
\hline 25. Snacks & 106 & 169 & 128 & 160 & 159 & 171 \\
\hline 26. Songs & 94 & 145 & 116 & 202 & 219 & 245 \\
\hline 27. Sports & 102 & 169 & 125 & 89 & 85 & 91 \\
\hline 28. Superheroes & 97 & 161 & 117 & 90 & 126 & 84 \\
\hline 29. Television shows & 106 & 161 & 123 & 188 & 236 & 221 \\
\hline 30. Toys & 111 & 168 & 128 & 238 & 345 & 271 \\
\hline 31. Vacation activities & 97 & 161 & 124 & 207 & 314 & 231 \\
\hline 32. Vegetables & 108 & 173 & 125 & 74 & 72 & 72 \\
\hline 33. Vehicles & 100 & 164 & 126 & 143 & 217 & 166 \\
\hline 34. Weather & 106 & 171 & 126 & 71 & 93 & 70 \\
\hline
\end{tabular}

each category, the child was asked to list as many items in the category as possible (e.g., "Tell me all the different kinds of fruits you can think of"). The children were given $45 \mathrm{sec}$ per category to list as many exemplars as possible, and responses were recorded by an interviewer. Once the child appeared to have exhausted his/her ability to list items or $45 \mathrm{sec}$ had elapsed, the researcher introduced the next category. It was emphasized to the children that there were no correct or incorrect answers and that they should respond with any responses they deemed appropriate. Six random orders of the 33 categories were presented, with the exception that the categories that were expected to have some overlap with another category (e.g., grocery store items and snacks) were separated by a minimum of four categories in order to reduce the children's reliance on previous responses.

\section{RESULTS AND DISCUSSION}

All the responses were compiled independently for each category overall, by each of three age categories (3-5 years, 6-8 years, and $9-12$ years). Table 1 displays the number of children who provided at least one exemplar for each category and the number of distinct exemplars reported per category for each age group. Some children were unable to generate any exemplars for some categories, and thus, the number of children responding to each category is unequal. Furthermore, due to the unequal numbers of children in each age group, a cursory examination and comparison between age groups of the frequencies of reported items could be misleading (i.e., 6- to 8-year-old children may be seen as more highly endorsing a particular item than are the other age groups). To compare across ages, percentages were calculated by dividing the reported frequency by the total number of respondents for that category and multiplying by 100 .

All responses were recorded, regardless of whether or not the researchers believed that the item was a member of the respective category. The rank order of all the responses was also recorded. Table 2 presents an example of the normative data for the category Animals. The remaining tables are downloadable from the Psychonomic Society Archive. Only the top 20 exemplars are reported, because there was a great deal of variability in the children's reports of less common exemplars. For instance, there were 730 different responses to the jobs category and 510 exemplars that were reported by only 1 child each. Had we included all the responses, this report would have been prohibitively long. When multiple exemplars fell in the 20th position, all are reported.

The 2 nd column contains the overall percentage of times that each item was mentioned (of all the items mentioned in that category) across all age groups. The percentage reporting information for each age group is then provided in each table (columns 4, 6, and 8). For each of the columns reporting overall data, the percentage of times the corresponding item was listed first is provided beside the overall reported percentage. In the 10th column, the mean rank 
Table 2

Animals

\begin{tabular}{|c|c|c|c|c|c|c|c|c|c|}
\hline \multirow[b]{2}{*}{ Exemplar } & \multirow{2}{*}{$\begin{array}{c}\text { Overall } \\
\%\end{array}$} & \multirow{2}{*}{$\begin{array}{c}\text { Listed } \\
\text { First }\end{array}$} & \multicolumn{2}{|c|}{ 3-5 Years } & \multicolumn{2}{|c|}{$6-8$ Years } & \multicolumn{2}{|c|}{$9-12$ Years } & \multirow[b]{2}{*}{$R$} \\
\hline & & & Overall & First & Overall & First & Overall & First & \\
\hline Tiger & 41.46 & 11.46 & 36.94 & 9.01 & 43.20 & 11.83 & 43.08 & 12.31 & 3.41 \\
\hline Lion & 40.24 & 7.56 & 35.14 & 5.41 & 41.42 & 7.10 & 43.08 & 10.00 & 3.70 \\
\hline Dog & 38.54 & 10.49 & 37.84 & 12.61 & 39.05 & 8.88 & 29.59 & 8.28 & 3.42 \\
\hline Cat & 35.61 & 6.59 & 35.14 & 8.11 & 34.91 & 5.92 & 28.40 & 4.73 & 3.59 \\
\hline Giraffe & 28.54 & 8.29 & 8.05 & 2.43 & 28.99 & 9.47 & 20.71 & 4.73 & 3.72 \\
\hline Elephant & 25.12 & 2.43 & 22.52 & 0.90 & 24.85 & 5.33 & 21.30 & 2.37 & 4.17 \\
\hline Cheetah & 22.68 & 7.56 & 19.82 & 5.41 & 22.49 & 8.88 & 19.53 & 5.92 & 3.62 \\
\hline Bird & 20.98 & 1.95 & 20.72 & 1.80 & 19.53 & 2.37 & 17.75 & 1.18 & 5.26 \\
\hline Bear & 19.76 & 4.63 & 19.82 & 5.41 & 18.93 & 5.33 & 15.98 & 2.37 & 4.10 \\
\hline Fish & 17.56 & 0.73 & 14.41 & 0.90 & 20.12 & 1.18 & 13.02 & 2.37 & 6.22 \\
\hline Horse & 16.83 & 3.41 & 21.62 & 4.50 & 16.57 & 2.96 & 10.06 & 2.37 & 4.23 \\
\hline Zebra & 16.59 & 3.17 & 10.81 & 2.70 & 17.75 & 2.96 & 15.38 & 2.96 & 4.04 \\
\hline Monkey & 16.59 & 1.22 & 18.92 & 0.90 & 14.20 & 1.78 & 13.61 & 0.60 & 5.19 \\
\hline Rabbit & 13.41 & 1.71 & 21.62 & 1.80 & 11.24 & 1.78 & 7.10 & 1.18 & 4.31 \\
\hline Snake & 13.41 & 1.22 & 9.99 & 1.80 & 14.20 & 0.59 & 11.83 & 1.18 & 5.11 \\
\hline Cow & 10.73 & 1.22 & 13.51 & 1.80 & 7.69 & 0.59 & 9.47 & 1.18 & 4.64 \\
\hline Deer & 10.49 & 3.17 & 10.81 & 4.50 & 8.28 & 1.78 & 10.06 & 2.96 & 3.63 \\
\hline Wolf & 9.02 & 0.24 & 9.99 & 0.00 & 7.69 & 0.59 & 10.00 & 0.00 & 6.11 \\
\hline Pig & 8.78 & 1.46 & 11.71 & 2.70 & 8.28 & 1.18 & 5.33 & 0.60 & 5.22 \\
\hline Kangaroo & 8.54 & 0.49 & 5.41 & 0.00 & 7.10 & 0.59 & 10.06 & 0.60 & 5.31 \\
\hline
\end{tabular}

position $(R)$ of the exemplar is presented. For example, if a child listed banana as an item in the fruit category first and another child listed banana second, the mean rank position for banana would be 1.5 . When extremely similar responses were recorded (e.g., fog and foggy), the items were combined to form one item; however, in keeping with Battig and Montague (1969), we strove to maintain the language used by the participants as much as possible. As such, there are responses within a single category that are similar but presented separately (e.g., couch and sofa). Most of the categories show consistency on high-frequency items; however, an important limitation of this data set is that some of these norms may have limited generalizability across historical and geographic space. Although this is true of most norm studies, it may be particularly true of some of the categories presented here (e.g., television shows), although less so of others (e.g., colors). Careful judgment should be exercised when these norms are used.

The present study showed substantially more variability within some categories than that found with adults. That is, Battig and Montague (1969) were able to list all the reported exemplars in their published report, whereas we were prohibited from doing so on the basis of sheer volume. However, there was also a high level of agreement between the Battig and Montague norms and the present set on many items (e.g., color, parts of the human body, and furniture). Of the 17 categories in the present study with substantive overlap with Battig and Montague's categories, only 4 (girls'names, boys' names, jobs/occupations, and toys) had fewer than 6 of the top 10 items in common. This finding bodes well for use of many of these categories in research that seeks to manipulate the level of similarity of items.

\section{REFERENCES}

Battig, W. F., \& Montague, W. E. (1969). Category norms for verbal items in 56 categories: A replication and extension of the Connecticut category norms. Journal of Experimental Psychology Monographs, 80, 1-46.

Casey, P. J., \& Heath, R. A. (1988). Category norms for Australians. Australian Journal of Psychology, 40, 323-339.

Connolly, D. A., \& Price, H. L. (2006). Children's suggestibility for an instance of a repeated event versus a unique event: The effect of degree of association between variable details. Journal of Experimental Child Psychology, 93, 207-223.

Marshall, C. E., \& PARR, W. V. (1996). New Zealand norms for a subset of Battig and Montague's (1969) categories. New Zealand Journal of Psychology, 25, 24-29.

Posnansky, C. J. (1978). Category norms for verbal items in 25 categories for children in Grades 2-6. Behavior Research Methods \& Instrumentation, 10, 819-832.

RAKISON, D. H., \& OAKES, L. M. (EDS.) (2003). Early category and concept development: Making sense of the blooming, buzzing confusion. Oxford: Oxford University Press

Shapiro, S. I., \& Palermo, D. S. (1970). Conceptual organization and class membership: Normative data for representatives of 100 categories. Psychonomic Monograph Supplements, 3, 107-127.

STORMs, G. (2001). Flemish category norms for exemplars of 39 categories: A replication of the Battig and Montague (1969) category norms. Psychologica Belgica, 41, 145-168.

\section{ARCHIVED MATERIALS}

The following materials [and links] associated with this article may be accessed through the Psychonomic Society's Norms, Stimuli, and Data archive, http://www.psychonomic.org/archive.

To access these files [or links], search the archive for this article using the journal name (Behavior Research Methods), the first author's name (Price) and the publication year (2006).

FILE: Price-BRM-2006.zip

DESCRIPTION: The compressed archive file contains two files:

PriceEtAl(InPress).txt, containing Tables 3-34. Number of distinct exemplars generated per category and number of children responding.

PriceEtAl(InPress).xls, containing the above information in Excel spreadsheet format.

AUTHOR's E-MAIL ADDRESS: hlprice@sfu.ca.

(Manuscript received November 17, 2004; revision accepted for publication May 17, 2005.) 